\title{
Aesthetic Education as a Topical Direction of Preparation of a Modern Specialist
}

\author{
Olena F. Sbitnieva \\ Borys Grinchenko Kyiv University, Kyiv, Ukraine \\ https://orcid.org/0000-0002-2201-2120 \\ Liudmyla M. Sbitnieva \\ Luhansk Taras Shevchenko National University, Starobilsk, Ukraine \\ https://orcid.org/0000-0001-5370-531X \\ Hanna E. Ovcharenko \\ Kyiv Municipal Academy of Variety and Circus Art, Kyiv, Ukraine \\ https://orcid.org/0000-0001-8648-6694 \\ Victoria S. Furkalo and Svitlana S. Bondar \\ Pavlo Tychyna Uman State Pedagogical University, Uman, Ukraine \\ https:// orcid.org/0000-0002-0502-3207 \\ https://orcid.org/0000-0001-6159-2159
}

\begin{abstract}
This article explores the problem of aesthetic education and focuses on issues related to its implementation in the educational process of a modern educational institution. The content and features of modern aesthetic education in the system of professional training of future specialists are covered. The study was conducted during the 2018/2019 academic year. The experimental group consisted of 105 students aged between 17-19 years, while the control group consisted of 155 students of the same ages. As part of this summative assessment, a survey was conducted with the help of a questionnaire, which involved a total of 260 students from both universities, who answered the questions specifying the main shortcomings of modern educational activities. It is known that one of the conditions that interferes with aesthetic development of future specialists is the lack of free time, due to the fact that most students work in their free time after classes and the lack of motivation to participate in classroom discussions. In the process of conducting summative assessment with the help of psychological methods, the main attention was focused on communicative and organizational abilities, empathy, creativity and reflection. It is noted that among the priorities of educational activities at the faculty, it is important to create appropriate aesthetic conditions for the active development of students. Based on the survey, it was found that the main methods in aesthetic education are training, creative meetings with experts, artists and writers; practicals (method of assignments, setting of
\end{abstract}


practical tasks - involvement in creative activity); preparation of excursions to museums, theatres, cinemas and the creation of thematic exhibitions. It is determined that studying at the university is not only preparation for future professional activities, but also the formation of character, inculcation of aesthetic and moral values, sustenance of culture and the development of creative thinking. The use of relevant international experience in the processes of creative preparation of young people plays an important role in ensuring the effectiveness of training and aesthetic education of students.

Keywords: aesthetic education; spirituality; methods; creativity; values

\section{Introduction}

Due to Ukraine's integration into the European educational space, modern education should be aimed at shaping the national spiritual revival of student youth. The solution of urgent problems of becoming a harmonious personality and shaping its civic consciousness, the ability to understand and multiply the values of spiritual culture is of particular importance. In the $21^{\text {st }}$ century, higher education in the world educational space strives for internationalization and international integration, while preserving its specifics. This occurs in the field of common approaches to the development of a comprehensively developed personality, system, content, method, forms of education, important moral and ethical values and directions of the educational process, in the tendencies of reforming education, innovation, creation of joint projects (Bitaev, 2004).

In addition, it should be emphasized that the emergence of spiritual impoverishment in young people is currently observed in the educational field. This problem is currently widespread, but for countries of different levels of socio-economic development, the possibilities of progress in the educational field in different pedagogical technologies may not be similar (Batrak, 2015). To solve these problems, it is essential to use aesthetic values by future specialists. Therefore, the main task facing the higher school today is to educate a highly cultured person, a true professional, with the purpose of further building their lives according to the laws of harmony and beauty of the world. It follows that building a process for the effective organization of aesthetic education of future specialists is important in pedagogical education (Skrypnikova, 2015).

This process is ensured by the main provisions presented in the National Doctrine for the Development of Education of Ukraine in the $21^{\text {st }}$ Century, the National State Comprehensive Program of Aesthetic Education, which traces the need for consistent and effective solution of the problems of aesthetic education of student youth, development of planetary thinking, preparation for its comprehensive world perception and creative knowledge of the aesthetic phenomena of life, works of art. Therefore, the above urges the problem of theoretical study of aesthetic education in the context of contemporary needs of Ukrainian society, substantiation of already existing concepts that take into account the aesthetic development of the future specialist, consideration of appropriate pedagogical conditions in order to increase the level of aesthetic culture of student youth is becoming urgent. 


\section{Research methodology}

The study is prolonged. It was conducted using general scientific theoretical, empirical and statistical methods of research and analysis of results according to the objective of each stage.

\subsection{Research Design}

The influence of aesthetic education on the formation of the aesthetic development of the future specialist is analyzed using aesthetic-oriented interactive methods, forms and means. In conducting the research, we were guided by modern requirements to the methods selected in accordance with the goal and objectives of the study. The following research methods were used to solve our research objectives: analysis and generalization of scientific and methodological literature and documents, pedagogical observation and pedagogical experiment and sociological \& psychological research methods.

The analysis and generalization of scientific and methodological literature on the topic of this research made it possible to systematize, comprehend, compare the scientific significance of specialized information from publications of foreign scholars. Attention was paid to the following issues: requirements of professional activity of future specialists and development of students' personal and professional qualities, study of students' attitude to aesthetic education, study of peculiarities of organization of content, forms and methods of aestheticoriented educational activities.

\subsection{Sociological methods}

Survey techniques were used: interview and questionnaire. Student questionnaire has been developed. The survey was conducted in accordance with the main provisions and requirements for sociological research in order to: determine the attitude of future specialists to the problems of organization of aesthetic education, identify the positive and negative sides of the educational process and evaluate the effectiveness of aesthetic education, its sections and forms. The method of conversation was used to get acquainted with students, study the person, identify strengths and weaknesses in their personal preparation and professional training, for feedback on the correction of the organization and content of aesthetic education of student youth.

The pedagogical observations were conducted at the Luhansk Taras Shevchenko National University, Institute of Culture and Arts in order to identify several aspects of the study of student youth, namely: revealing the content of psychological and pedagogical conditions of formation of a modern specialist in the process of aesthetic education, identifying the relationship between the educational process and aesthetic education, studying the process of formation of personal and professional qualities as a basis for successful professional activity of future specialists and improving the process of aesthetic education, which will contribute to the effective formation of personal and professional qualities of specialists by means, methods and forms of work.

The study was organized according to the requirements and was carried out during the 2018/2019 academic year at the Luhansk Taras Shevchenko National 
University, Institute of Culture and Arts with 105 students aged between 17-19 years (experimental group). The control group consisted of 155 students aged between 17-19 years from the Kyiv National University of Culture and Arts at the Faculty of Performing Arts.

The experimental part of the study was divided into several stages. At the first stage, the search, analysis and generalization of data of scientific, methodological and specialized literature and documents were carried out. The research work of this stage has allowed revealing problems of educational work of modern youth and passing to the substantiation and development of their vision of aesthetic education of modern specialists. At the second stage, in the course of the summative assessment, a survey of students of the 1st-2nd years of study $(\mathrm{n}=105)$ studying at the Luhansk Taras Shevchenko National University, the Institute of Culture and Arts was conducted in order to analyze the current state and identify problems of aesthetic education in an educational institution.

Based on the analysis of the literature, the answers of the respondents, the data obtained and the results of the pedagogical experiment, the program of aesthetic education was theoretically substantiated in order to improve the personal and professional formation of future specialists. The structure of aesthetic-oriented educational activity was developed, priority personal and professional qualities were determined, comparative analysis of performed control exercises was carried out. A formative assessment was conducted to test the effectiveness of the proposed aesthetic education program for modern specialists. The results were compared in the control group (155 students) and the experimental group (105 students).

At the third stage, the results of the research and experimental work were analyzed and generalized, the conclusions and practical recommendations were drawn. The pedagogical experiment was conducted in order to scientifically substantiate, develop and experimentally test students' impressions of the forms of educational activities.

\subsection{Analysis of key research and publications}

A detailed analysis of the scientific and pedagogical literature shows that the main aspects of aesthetic education were considered in their scientific works by well-known teachers. It should be noted that philosophical foundations of aesthetic education (Bitaev, 2004; Gurina, 2005); cultural aspects (Petrova, 2007); pedagogical aspects (Skrypnikova, 2015) made significant contributions to the study of the problem. Important contribution was also made by foreign scholars Kumar (2014), Maravilhas (2015), who considered the humanitarization of education as a process of its culturalization in their works. The objective of the article was to analyze the essence and peculiarities of aesthetic education as a topical direction of preparation of a modern specialist. 


\section{Results}

It is well known that the main purpose of students in higher educational institutions is to acquire professional knowledge. But it should be noted that higher educational institutions prepare not only for future professional activity, but also for the formation of moral, emotional and aesthetic values, etc. Therefore, a university shall introduce activities for further formation of aesthetic attitude of future specialists towards the world and themselves in the first place, to the environment, and the desire to join the world of values, to improve themselves physically and spiritually, to enhance aesthetic qualities and so on. On the basis of the analysis of scientific and pedagogical literature and practice, various interpretations of the essence of the concept of "aesthetic education" were analyzed, which are presented in more detail in Table 1.

Table 1: Scholars' views on determination of "aesthetic education"

\begin{tabular}{|c|c|c|c|}
\hline $\begin{array}{c}\text { Item } \\
\text { No. }\end{array}$ & Authors & \multicolumn{1}{c|}{$\begin{array}{c}\text { Definition of the concept of "aesthetic education" } \\
\text { Shevchenko } \\
(2010)\end{array}$} & $\begin{array}{l}\text { the process of objectification and appropriation of aesthetic } \\
\text { values by the subject through formation of aesthetic attitude } \\
\text { towards them and intensification of creative artistic and } \\
\text { aesthetic activity }\end{array}$ \\
\hline 2 & $\begin{array}{c}\text { Sharata and } \\
\text { Kedis } \\
(2018)\end{array}$ & $\begin{array}{l}\text { the process of acquiring artistic knowledge and skills; a means } \\
\text { of personal development based on the identification of: creative } \\
\text { abilities of future specialists, their professional abilities, } \\
\text { musical, aesthetic needs and interests based on the historical } \\
\text { experience of their people, acceptance of multicultural space, } \\
\text { value attitude to ethno-national specifics }\end{array}$ \\
\hline 3 & $\begin{array}{l}\text { Batrak } \\
\text { (2015) }\end{array}$ & $\begin{array}{l}\text { purposeful process aimed at developing a modern socially and } \\
\text { creatively active person with a conscious life position, formed } \\
\text { on the examples of eternal human values and high culture, able } \\
\text { to critically perceive reality and bring beauty to the process and } \\
\text { result of life in all its manifestations }\end{array}$ \\
\hline $\begin{array}{l}\text { Bitaev } \\
(2004)\end{array}$ & $\begin{array}{l}\text { sees the essence of aesthetic education in the formation of a } \\
\text { "universal worldview of a man, combining both artistic and } \\
\text { moral, thus representing the unity of truth, good and beauty of } \\
\text { human being" and states that "aesthetic education based on art } \\
\text { seeks to develop the person universally, transferring experience } \\
\text { to the individual, and through it - the total experience of } \\
\text { human being. In this way, the process of human creation goes } \\
\text { on, its ability to think is activated, a sensual culture is formed." }\end{array}$ \\
\hline
\end{tabular}

Analyzing the views of scholars, we note that according to the educational program of training future specialists, which is aimed at personal and professional development of an individual, the acquisition of integrated knowledge, skills, formation of an educated individual capable of selfdevelopment and self-knowledge, professional mobility, successful adaptation to changes in different spheres of life and labor management in a competitive market economy. But first of all, in today's society, the development of the spiritual and aesthetic qualities of future specialists is worth consideration. 
Therefore, the main purpose of aesthetic education in educational institutions is the formation of an aesthetic culture - the opportunity for aesthetic mastery of the world, spiritual growth of personality, assimilation and transformation of the world and himself. The main result of successful aesthetic education is a comprehensively and harmoniously developed individual, which combines high ideological beliefs, moral qualities, aesthetic values (Ushakova, 2015). In higher educational institutions, the main tasks of aesthetic education of the future specialist are the formation of creative abilities, aesthetic motives, interests; aesthetic concepts, views and beliefs and true aesthetic and spiritual values; development of students' aesthetic tastes; acquaintance with national and world cultural heritage, with contemporary art; forming the readiness of graduates of higher educational institutions to introduce aesthetic education in their future life and the improvement of artistic literacy (Tserklevych \& Kyrylyuk, 2015).

The following aesthetic components are used in the educational process of higher education institutions during aesthetic education: aesthetic perception, aesthetic attitude, aesthetic feeling, aesthetic judgment, aesthetic ideal, aesthetic taste and aesthetic activity. In the process of pedagogical activity, it is necessary to include the general culture, intelligence of the teacher and the student; emotional saturation and expressiveness of educational material; the culture of thought and the beauty of the world and the knowledge of arts and aesthetic experiences (Shevchenko, 2010). The aesthetic education during which the aesthetic culture is formed and the creative abilities of future specialists should be realized in the interaction of lecturers, mentors, tutors, advisors and students. Within the pedagogical process, it is the supervisors and the mentors who are the subjects of aesthetic education and the students are the objects of education (Radkevych, 2000). Lecturers, mentors and supervisors play an important role in the process of aesthetic education of the future specialist, since a comprehensive and harmonious formation of students depends on personal and professional abilities of the subjects of education (Tserklevych \& Kyrylyuk, 2015).

The next step in the summative experiment was a survey involving a total of 260 students from the Luhansk Taras Shevchenko National University, the Institute of Culture and Arts, and the Kyiv National University of Culture and Arts, which identified the major drawbacks of modern educational activities work when providing answers to the questions. The results are presented in Table 2.

Table 2: The main disadvantages of modern educational work (\%)

\begin{tabular}{|l|c|c|}
\hline Disadvantages & $\begin{array}{c}\text { Experimental } \\
\text { group }\end{array}$ & $\begin{array}{c}\text { Control } \\
\text { group }\end{array}$ \\
\hline Lack of proper pedagogical conditions & 24 & 13 \\
\hline Lack of free time for classes & 42 & 19 \\
\hline Lack of motivation to participate in aesthetic activities & 22 & 42 \\
\hline $\begin{array}{l}\text { Insufficient attention of lecturers and supervisors to } \\
\text { educational activities }\end{array}$ & 5 & 7 \\
\hline No need for aesthetic education, because they work daily & 5 & 8 \\
\hline Other & 2 & 11 \\
\hline
\end{tabular}


One of the conditions that hinder future professionals from aesthetic development is known to be lack of free time due to the fact that most students work in their free time after classes and lack of motivation to take part in sessions held by tutors. In the process of conducting the summative assessment with the help of psychological methods, the main attention was focused on the communicative and organizational abilities, which are of great importance for modern specialists, since communicativeness synthesizes various elements of the outlook, moral, professional, physical and emotional-volitional qualities of student youth, as well as special knowledge, skills and abilities that influence the means of transferring, using and storing information. Reflection, analysis of one's professional activity, actions, behavior; critical analysis and determination of ways of constructive improvement of their activity is carried out with the help of professional reflection through the Method of Studying the Level of Reflection.

An integral feature of the future specialist's personality as one element of the development of aesthetic and moral values is creativity, which is manifested in the student's ability to think outside the box and behavior, as well as to the awareness and development of professional and life experience. On this basis, we can say that thinking is related to the accumulation of facts that are promising for science at the present stage of society development. According to Petrova (2007) and Belyalova (2014), one of the components of a research culture is exploratory thinking as the ability to generate new knowledge. They emphasize that research thinking is related to self-exploration, research skills and personality traits that are part of the research culture. Kumar (2014) believes, that research thinking is a logical and rational way of thinking that prompts us to explore every aspect of emerging problems. Therefore, the method of Vartega "Circle" was used in the study.

Effective professional activity is supported by empathy as "understanding the emotional state, penetration into the experience of another person." The Methods of Diagnostics of the Level of Empathic Abilities were used for this purpose. The use of empathy in teaching helps students succeed, positively engages with students, enhances the social and emotional component of learning (Warren, 2017), motivates and enhances student performance (Arghode, Yalvac \& Liew, 2013). Based on the analysis of the results of the Motivation to Learning at Higher Educational Institution methodology, it is found that the majority of students of higher educational institution seek only a diploma of higher education, but do not want to develop or to form an aesthetic culture for mastering their professional activity. Attention was paid to motivation, reflection, creativity, empathy, communication and organizational skills.

Another methodology was the Self-actualization Test, where all students have a sufficient level (58\%) on the scale of "value orientations", thus confirming their orientation to the society in which they live, to its ideals, norms, rules. In accordance with the society's guidelines, youth builds their value system based on their needs and motives, i.e. the value system and its hierarchy are individual for each student. The lowest scores on the cognition and creativity scales were obtained by the specialists of the Kyiv National University of Culture and Arts, 
while the students - the future specialists of the Luhansk Taras Shevchenko National University, the Institute of Culture and Arts had a sufficient level of these indicators, which can be explained by the inertness of many students, their personal transformation in the conditions of the modern society, which are manifested in the loss of or indistinct awareness of their own professional prospects after graduation, over-emphasis on material incentives to perform one or another activity. Data on the results of the study for each of the methods are provided in Table 3.

Table 3: Comparative characteristics of the results of the study of future specialists

\begin{tabular}{|c|c|c|c|c|c|c|c|}
\hline & \multicolumn{3}{|c|}{ Experimental group, \% } & \multicolumn{3}{|c|}{ Control group, $\%$} \\
\hline & & $\mathbf{H}$ & C & B & $\mathbf{H}$ & $\mathrm{C}$ & B \\
\hline \multicolumn{2}{|c|}{ Communicative } & 62 & 11 & 27 & 41 & 21 & 38 \\
\hline \multicolumn{2}{|c|}{ Organizational abilities } & 58 & 15 & 27 & 53 & 19 & 34 \\
\hline \multicolumn{2}{|c|}{ Reflection } & 62 & 62 & 26 & 11 & 59 & 31 \\
\hline \multicolumn{2}{|c|}{ Creativity } & 29 & 29 & 49 & 22 & 26 & 52 \\
\hline \multicolumn{2}{|c|}{ Empathy } & 64 & 64 & 28 & 8 & 59 & 23 \\
\hline \multicolumn{2}{|c|}{ Acquisition of knowledge } & 47 & 42 & 11 & 55 & 39 & 16 \\
\hline \multirow{2}{*}{ 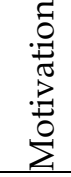 } & Mastery of profession & 46 & 38 & 16 & 31 & 44 & 25 \\
\hline & Getting a diploma & 3 & 15 & 82 & 4 & 12 & 84 \\
\hline
\end{tabular}

Analyzing the data obtained, we find that students have productive educational activities. Having analyzed the results presented above, we can draw the following conclusion: the development of the personal and professional qualities of future specialists is not sufficient for the formation of aesthetic culture.

\section{Discussion}

The development of techniques for the use of interactive technologies for higher education (Bodin, Marty \& Carron, 2011) are of particular importance for our study. The use of educational games as a way to model the conditional professional environment makes it possible to "include" the student in the scientific model of the theory of professional activity (Bellotti et al., 2011). The effectiveness of the process of aesthetic education of future specialists depends on the intended use of interactive and creative methods of work by lecturers, supervisors, mentors, such as a case-method, round-table method, project method, discussions, business games, role-playing games, supervisor's hours, conversations, creative competitions, musical evenings, exhibitions of creative works and the like. The main means of aesthetic education of students are education, work, life, communication, creativity, literature and art. 
The Institute of Culture and Arts paid considerable attention to the formation of aesthetic culture and tastes in students. Among the advantages of educational activities at the faculty, the basic is building educational process, which is aimed at comprehensive and harmonious development, creative self-development and self-realization of a young specialist, development of creativity and creative thinking. This is implemented in the process of cultural and aesthetic activities, which helps the student further increase the level of aesthetic culture and acquire a creative potential. Moreover, creativity has been at the heart of the innovations underlying student competitiveness (Chen \& Chen 2012). The creative thinking style of people has become a platform for new economic and social trends (Černetič, 2012), information society (Maravilhas, 2015) and a creative economy (Araya \& Peters, 2010). According to Radovic (2016), creative thinking is a synergy of cognition and personality traits that enables a person to apply his or her intellectual abilities and knowledge to solve a problem using a figurative and experimental approach.

Aesthetic education involves the development of knowledge, the ability to multiply the cultural and artistic heritage of the people, to feel and reproduce the beautiful things in their lives, the development of aesthetic needs and feelings, moral and aesthetic values, as well as creative activities (Petrova, 2007). It should be noted that during the aesthetic education at the Luhansk Taras Shevchenko National University, the Institute of Culture and Arts, the project method Moral and Aesthetic Culture of the Modern Specialist was implemented in order to form productive knowledge. The purpose was to teach students to think, find and solve problems independently, using knowledge from different fields, to form integrative skills, to predict results and possible consequences of different solutions and the ability to establish cause and effect relationships. Training Development of Aesthetic Culture includes exercises such as emotions and creativity, dialogue with art, emotional intelligence and others. This was conducted with the purpose of assimilating knowledge, developing skills, abilities, formation of attitudes and increasing competence in a certain sphere of life. Professional training for future specialists becomes more effective if there is an active interaction between students and teaching staff in the educational process and if they learn and practice these skills.

Therefore, the use of training contributes to the overall formation of a culture of interaction. Viewing and discussing videos on the topic, Beautiful and Ugly in Art, helps to cover artistic problems and the problems of aesthetic education of modern students. The conference on the topic, Formation of the Aesthetic Culture of Student Youth - the Key to Successful Harmonious Personality, was held with the participation of teachers and students, which discussed the problems and prospects of aesthetic education in a modern educational institution through questions and answers. In addition, the Word about Ukraine Speech Contest was held on the Day of National Unity of Ukraine and the commemoration of the Heavenly Hundred Heroes (people killed during the 2014 Revolution). Students presented their patriotic speeches with emotions, sincerity, extraordinary passion and dedication, which impressed those present. Furthermore, students had the opportunity to visit the Park of Partisan Glory at the Chervonyi Khutir in Kyiv. 
An excursion to the memorial park and an interesting story about the heroic past of our people made young people think about the fates of those who gave their lives for the sake of future generations; the University Open Photo Contest "The World through the Eyes of Students"; the briefing was held: Aesthetic Competence as One of the Important Components of Professional Development of a Future Specialist during which the following issues were analyzed and discussed: "Aesthetic culture in the system of professional activity", "Aesthetic culture and worldview orientations of the future profession", "Aesthetic taste and aesthetic thinking", "Aesthetic knowledge in the chosen profession". During the lesson, students were provided with information material on the structure of aesthetic culture, analyzed the differences between aesthetic outlook and aesthetic culture, detailing each component of the structure of aesthetic culture. In order to work independently, students were asked to analyze each of the components of aesthetic culture in accordance with the scientific approaches of contemporary national and foreign scholars, etc.

The educational process in higher educational institutions is aimed at the aesthetic development of an individual. Each subject taught in higher educational institutions has opportunities for aesthetic education of a modern specialist. All forms of educational activity - lectures, seminars, practical classes, trainings - are characterized by a certain level of aesthetic load. It is individual classes that not only give knowledge but create creative thinking. Lecturers, supervisors teach students in the process of educational activities to see the beauty in their actions, to understand the aesthetic aspects in joint activity, in the process of teamwork. For example, in social studies, lecturers have the opportunity to show students all the beauty of the enthusiastic and heroic. In addition, the study of such subjects as Ethics, Cultural Studies, Aesthetics, Ukrainian and Foreign Languages, Psychology and Acting Skills play a significant role in the aesthetic education of modern specialists (Shevchenko, 2010). The work of Keller et al. (2016) attracted much attention as they believed that the teacher has to invest his time, his love and his energy in the development of the student's personality. In order to establish a harmonious relationship with students, consultations were organized with the supervisors, where they created a trustful atmosphere and helped solve the educational problems of preparation.

Consultations with students were conducted on the basis of the following questions: "How do you see yourself in 5 years in your future professional activity?", "How is it possible to form your own aesthetic culture?", "What are the problems in the aesthetic education of your higher educational institution?"

Thus, the high schools use various forms of aesthetic education (traditional and innovative), which were determined by the creative and innovative approach of lecturers, supervisors, mentors, and tutors. In the process of educational work, an aesthetically favorable atmosphere was created. It was aimed at the effectiveness of aesthetic education of students at the faculty. This ensures the development of a high level of aesthetic culture of a modern specialist. In addition, famous cultural figures were involved in educational events, cultural meetings. Also, cultural excursions with artists and writers were organized. That 
is, based on the literature (Kavanagh et al., 2019), it should be noted that lecturers have to independently choose such methods, forms and tools that they believe will help students develop their aesthetic culture, spirituality, aesthetic taste, creativity, etc. In this area, various educational activities of aesthetic orientation were of great importance, conducted by lecturers, supervisors, mentors at the student dormitory, namely: Student's Day, Culture of Communication in the Dormitory, Respect your Roommates, Exterior Appearance and Culture of Behavior, a contest for the best dormitory room.

It should be noted that a survey was conducted on the topic: "Your Impressions of the Forms of Educational Activities" among students of the Luhansk Taras Shevchenko National University, the Institute of Culture and Arts. The survey involved 260 students. Analyzing the results obtained, we find that the positive influence of the introduced forms and methods of educational activities, which contributed to the cultural and aesthetic development and acquisition of moral and aesthetic values by the students, their desire to achieve the aesthetic ideal, the formation of aesthetic feelings, needs, tastes, that make it possible to increase the efficiency of forming manners in modern specialists.

Based on the survey, it was determined that the following methods were most effective in aesthetic educational activities: (trainings - 70\% of respondents), creative meetings with artists, writers - 85\%; practical (method of assignments, projects, case study, setting practical tasks - engaging in active creative activity $68 \%$ ); preparation of excursions to museums, theatres, cinemas; creation of thematic exhibitions $-75 \%$, briefing ( $56 \%$ of respondents), business and roleplaying games (77\% of respondents), the students like lectures the least (38\%), because, as students stated, they occupy a passive position in this form of activities. The developed criteria and the system of psychological and pedagogical tests and methods of diagnostics were used to obtain the necessary data for determining the levels of formation of components of readiness for aesthetic development. At this stage, the students of the control and experimental groups were diagnosed. The data obtained during this diagnosis are presented in Table 4.

Table 4: Diagnosis results

\begin{tabular}{|l|c|c|c|c|c|c|}
\hline \multirow{2}{*}{ Criterion } & \multicolumn{5}{|c|}{$\%$ of persons at the appropriate level } \\
\cline { 2 - 7 } & \multicolumn{2}{|c|}{ Professional } & \multicolumn{2}{c|}{ Professional } & \multicolumn{2}{c|}{ Professional } \\
\cline { 2 - 7 } & EG \% & CG \% & EG \% & CG \% & EG \% & CG \% \\
\hline Communicative & $1.72 \%$ & $29.31 \%$ & $3.45 \%$ & $14.65 \%$ & $42.24 \%$ & $8.62 \%$ \\
\hline $\begin{array}{l}\text { Moral and } \\
\text { aesthetic }\end{array}$ & $2.58 \%$ & $31.03 \%$ & $13.79 \%$ & $15.52 \%$ & $31.03 \%$ & $6.03 \%$ \\
\hline Psychological & $0.86 \%$ & $38.79 \%$ & $18.96 \%$ & $9.48 \%$ & $27.58 \%$ & $4.31 \%$ \\
\hline Creative & $1.72 \%$ & $12.93 \%$ & $15.52 \%$ & $31.89 \%$ & $30.17 \%$ & $7.76 \%$ \\
\hline
\end{tabular}




\subsection{Results of the pedagogical experiment}

The results obtained indicate that it is advisable to divide students by three levels (basic, professional, and professionally specialized) according to four determined criteria. While at the stage of the summative assessment students with the basic level of communication criterion amounted to $62 \%$, after the formative assessment they amounted to $1.72 \%$, i.e. by $60.28 \%$ less. The formation of levels of moral and aesthetic criterion during the ascertaining experiment and after conducting the formative experiment is of particular interest. The data obtained during this diagnosis are presented in Table 5.

Table 5: Formation of the levels of moral and aesthetic criteria

\begin{tabular}{|l|c|c|}
\hline \multirow{2}{*}{ Levels } & \multicolumn{2}{|c|}{$\%$ of persons at the relevant level } \\
\cline { 2 - 3 } & Summative assessment & Formative assessment \\
\hline Basic & $47 \%$ & $2.58 \%$ \\
\hline Professional & $38 \%$ & $13.79 \%$ \\
\hline Professionally specialized & $9 \%$ & $31.03 \%$ \\
\hline
\end{tabular}

The total number of students with a professionally-specialized level for moral and aesthetic criteria increased due to positive changes resulting from displacement of those students who had professional and basic levels: basic $47 \%$, after the formative assessment the figure became $2.58 \%$; professional - $38 \%$, after the experiment - 13,79\%; professionally specialized - $9 \%$, after conducting a formative assessment of students - $31.03 \%$. Future specialists with a professionally specialized (high) level of psychological criterion were characterized by personal maturity, emotional equilibrium, reflection and empathy, but students still experience some difficulties with independent assessment of some problem situations and conflict resolution. Thus, EG students at the Luhansk Taras Shevchenko National University underwent qualitative and quantitative changes due to the introduction of educational aesthetic activities, application of criteria and levels; implementation of trainings, conducting of classes, lectures using interactive methods, etc.

Therefore, the objectives of the management of the educational institution, lecturers, supervisors on aesthetic education are the development of special methods of aesthetic orientation, intensification of educational activities to involve students in various forms of educational activities, the organization of meetings with famous artists, writers, holding all-university competitions, trainings, role-playing and business games, organization of cultural leisure in the form of excursions to cultural monuments, and visits to the theatres and museums (Batrak, 2015). Therefore, the following indicators play an important role in the effective aesthetic education in higher educational institutions: the development of the aesthetic theory, which is the basis of aesthetic education; aesthetic orientation of lecturers in the educational process in order to develop the moral and ethical values of a modern specialist and spiritual values that will be important for the Ukrainian society (Skrypnikova, 2015). 


\section{Conclusions}

Aesthetic education is interpreted as the purposeful formation of aesthetic attitude of a person to reality. This is a specific type of socially significant activity carried out by the subject in relation to the object in order to develop a system of orientation in the world of moral and aesthetic values as regards the ideas established in modern society, about their nature and purpose (Yarmachenko, 2001). It has been determined that aesthetic education plays an important role in the system of professional training of modern specialists, develops moral and aesthetic values, creative thinking and spiritual abilities that future specialists will be able to use in the personal and professional sphere. It is also noted that lecturers, supervisors, mentors, and tutors have a special role in aesthetic education. Creating aesthetic conditions involves the joint activity of lecturers and students. Analyzing the process of aesthetic education at the Luhansk Taras Shevchenko National University, the Institute of Culture and Arts shows that the institution provides training of aesthetically competent specialists and forms a comprehensively developed, spiritual and cultural personality. In the process of education, individuals develop a system of values that structures the spiritual rebirth of the individual. It is spirituality as the basis of aesthetic education that helps people to aesthetically perceive the surrounding reality and develops the ability to be creative, to develop and use moral and aesthetic values, spiritual abilities in the professional sphere, in life, in actions and behavior. As a spatial limitation of the orientation process, the educational institution acts as the center of the society for the student in which he lives and acts in the period of self-determination. The process of formation of aesthetic orientations can be represented as the process of an individual ascending to aesthetic values. This aspect of the problem can become the basis for further research in the field of vocational education in order to organize the aesthetic, spiritual and moral education of students.

\section{Acknowledgements}

We are grateful to all members of the University for this research that we were able to complete it smoothly.

\section{References}

Araya, D., \& Peters, M. A. (Eds.). (2010). Education in the creative economy: Knowledge and learning in the age of innovation. New York, NY: Peter Lang.

Arghode, V., Yalvac, B., \& Liew, J. (2013). Teacher empathy and science education: A collective case study. Eurasia Journal of Mathematics, Science and Technology Education, 9(2), 89-99. https://doi.org/10.12973/eurasia.2013.921a

Batrak, T. V. (2015). Aesthetic education of students by means of foreign art culture as interdisciplanary problem. Scientific Issues of Ternopil Volodymyr Hnatiuk National Pedagogical University. Series: Pedagogy, 1, 195-201.

Bellotti, F., Ott, M., Arnab, S., Berta, R., Freitas, S. D., Kiili, K., \& De Gloria, A. (2011). Designing serious games for education: from pedagogical principles to game mechanisms. In D. Gouscos, \& M. Meimaris (Eds.), Proceedings of the 5th European Conference on Games Based Learning (pp. 26-34). Reading, UK: Academic Publishing International.

Belyalova, M. A. (2014). Research thinking and research abilities of the student in ensuring quality of modern professional education. International Journal of Experimental Education, 10, 78-81. 
Bitaev, V. A. (2004). Aesthetic education and humanization of the individual (Doctoral thesis). Volodymyr Dahl Eastern Ukrainian National University, Lugansk, Ukraine.

Bodin, M., Marty, J., \& Carron, T. (2011). Specifying collaborative tools in game-based learning environments: Clues from the trenches. In D. Gouscos, \& M. Meimaris (Eds.), Proceedings of the 5th European Conference on Games Based Learning (pp. 5-9). Reading, UK: Academic Publishing International.

Černetič, M. (2012). Education and knowledge-based economy. Metodički obzori, 7(3), 515.

Chen, J. K., \& Chen, I. S. (2012). Creative-oriented personality, creativity improvement and innovation level enhancement. Quality and Quantity, 46(5), 1625-1642.

Gurina, G. G. (Comp.). (2005). Aesthetics: dictionary of the most common terms (Ukrainian and Russian). Kharkiv, Ukraine: CDAC.

Kavanagh, S. S., Monte-Sano, C., Reisman, A., Fogo, B., McGrew, S., \& Cipparone, P. (2019). Teaching content in practice: Investigating rehearsals of social studies discussions. Teaching and Teacher Education, 86, Article 102863. https:// doi.org/10.1016/j.tate.2019.06.017

Keller, M. M., Hoy, A. W., Goetz, T., \& Frenzel, A. C. (2016). Teacher enthusiasm: Reviewing and redefining a complex construct. Educational Psychology Review, 28(4), 743-769.

Kumar, R. (2014). Research methodology: A step-by-step guide for beginners (4 ${ }^{\text {th }}$ ed.). Thousand Oaks, CA: SAGE.

Maravilhas, S. (2015). Challenges for education in the information society. Hershey, PA: IGI Global.

Petrova, N. V. (2007). Psychology and pedagogical essence of research culture of the personality. The Bulletin of the Adyghe State University: Internet Scientific Journal, 4. Retrieved from http://vestnik.adygnet.ru/files/2007.4/609/petrova2007_4.pdf

Radkevych, V. A. (2000). The concept of vocational education. Vocational and technical education, 2, 44-46.

Radovic, Z. (2016). Creative thinking - an essential skill for the 21st century. INKBOT DESIGN. Retrieved from https://inkbotdesign.com/creative-thinking/

Sharata, N., \& Kedis, O. (2018). Artistically-aesthetic education of student young people of the Mykolaiv national agrarian university. Scientific Herald of the Mykolaiv V. O. Sukhomlynskyi National University. Seria: Pedagogical Sciences, 1(60), 398-402.

Shevchenko, G. P. (2010). Nowadays development of aesthetic education in higher educational establishments of Ukraine. The Sources of Pedagogical Skills. Seria: Pedagogical Sciences, 7, 9-13.

Skrypnikova, S. V. (2015). The experience of aesthetic education in Ukraine: origins, current state and prospects of development. In T. I. Andrushchenko (Ed.), Aesthetic education of teacher: collective monograph (pp. 99-116). Kyiv, Ukraine: Publishing House of N. P. Dragomanov NPU.

Tserklevych, V. S., \& Kyrylyuk, Y. M. (2015). To the help of the curator of an academic group: an informative and methodical manual. Khmelnytskyi, Ukraine: KhKTEI.

Ushakova, I. (2015). The formation of the aesthetic image of man in student youth by the complex of arts (PhD thesis). Volodymyr Dahl Eastern Ukrainian National University, Kyiv, Ukraine.

Warren, C. A. (2017). Empathy, teacher dispositions, and preparation for culturally responsive pedagogy. Journal of Teacher Education, 69(2), 169-183.

Yarmachenko, M. D. (Ed.). (2001). Pedagogical Dictionary. Kyiv, Ukraine: Pedagogical Thought. 